EPJ Web of Conferences 45, 01125 (2013)

DOI: $10.1051 /$ epjconf/20134501125

(C) Owned by the authors, published by EDP Sciences, 2013

\title{
The structural design of the experimental equipment for unconventional heating water using heat transfer surfaces located in the heat source
}

\author{
K. Kaduchová ${ }^{1, a}$, R. Lenhard ${ }^{1}$, S. Gavlas ${ }^{1}$, and J. Jandačka ${ }^{1}$ \\ ${ }^{1}$ University of Žilina, Faculty of Mechanical Engineering, Department of Power Engineering, Univerzitna 1, \\ 01026 Žilina, Slovakia
}

\begin{abstract}
Flue gas temperature at throat of most industrially produced fireplaces is around 250 to $350{ }^{\circ} \mathrm{C}$. It's quite interesting thermal potential, which can be even before sucking up the chimney back utilize. One of the potential uses of this device to heat the hot water. Article refers to the structural design of such a device, which works with the transfer of heat through a substance changes phase from liquid to steam in a sealed tube (heat pipe). Benefits of heat pipes is their light weight, the thermal effect of a rapid and low maintenance costs.
\end{abstract}

\section{Introduction}

The trend in cooling systems is moving towards the use of natural convection cooling. One way is to change the heat transfer from the liquid phase of the substance to steam in a hermetically sealed tube. Such a device is called a heat pipe. Heat pipes have advantages over the most common devices with transporting heat in which heat transfer in the large temperature gradients at relatively short distances.
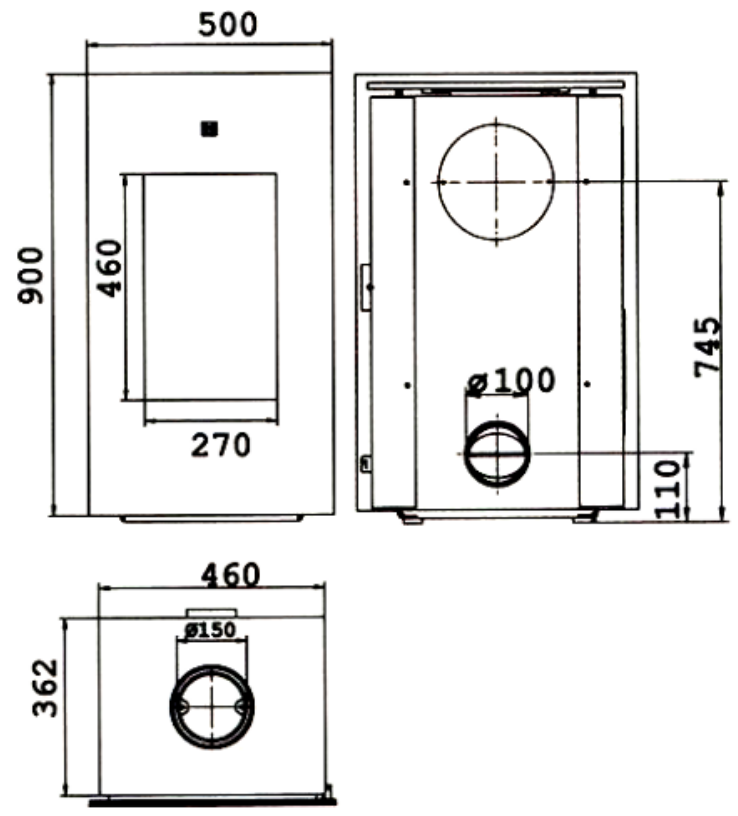

Fig. 1. Graphical representation of the heater - basic dimensions, 3D view.
When the heat pipe is the evaporation and condensation of the heat pipe temperature difference a few Celsius degrees. The cooling output can take the heat pipe smoothly and for longer distances. Benefits of heat pipes are their light weight, the thermal effect of a rapid and low maintenance costs. The device does not have moving parts, requires no maintenance, and has a very long life and production as well as the activity itself does not pollute the environment.

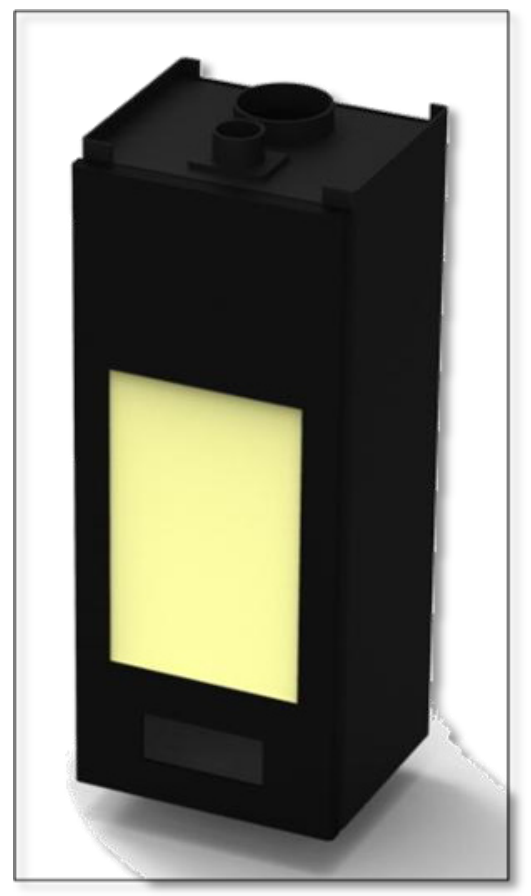

Fig. 2. Graphical representation of the heater - basic dimensions, 3D view.

akatarina.kaduchova@fstroj.uniza.sk 
Systems using heat pipes are usually used in industrial areas used in the production of thermal processes and technology. As the hydraulic and thermal processes occurring in changing phase working fluid are considerably complex, as well as the whole technology of tubes. The article highlights the structural design of the experimental facility. This facility will be used for unconventional hot water and heat sources are the combustion fireplace insert. The whole device was modeled using Pro/ENGINEER. It is a system that covers the entire development process, from conceptual design through simulation, and manufacturing. It is based on the parameterization of design elements and full associativity. In the following chapters will be given the great vastness of the problem only briefly describes the different design elements to its final version.

\section{Water heating}

Water heating in a small heat sources biomass is made by hot-water heat exchanger. Hot water heat exchangers are most often welded from sheet metal pressings or pipes are built into small sources (fireplaces), while allowing additional heating and water heating systems, heating and hot water. Most tend to be located between the fireplace and chimney or fireplace mantle in the second fireplace insert. Hot water can be directly connected to the heating system, or may be accumulated in the tray for later use. Fireplace inserts with hot-water heat exchanger is possible because of the design into two basic groups:

- Insert the directly integrated water exchanger.

- Insert the externally connected water exchanger.

\section{Fireplace insert}

It is a wood stove with a nominal capacity of $6 \mathrm{~kW}$, the efficiency is approximately $79 \%$ figure 1 . Carrier skelekt consists of a steel frame in the combustion chamber of the fireplaces is fitted skamolex to easily withstand the high combustion temperatures. They are designed for burning wood. Front tiles are glazed and operable. Connecting the venting can alternatively change the rear or top connection.

\section{Heat pipe and his principle}

Heat pipe figure 3 is a hermetically sealed tube, which contains the working medium (water, alcohol, freon, mercury, ammonia, helium,...) at a defined pressure. Heating one end of the tube and discharged at the other end causes the "hot" end of the tube will start working medium in the form of a liquid to evaporate, steam pipe passes through the "cold" end, there condense back into a liquid by gravity or capillary action through absorption liquid substance passes back to a "hot" end which again evaporated. This result in a forced circulation of the working media associated with heat transfer. The device thus operates only when the temperature gradient (only if there is a difference in the temperatures at the ends of the heat pipe). The greater the difference, the greater heat transfer efficiency.

Media used depends on the temperature range the tube temperature at which the evaporation and condensation of the working media.
From Computer Desktop Encyclopedia (1) 2004 The Computer Language $\mathrm{Co}$. Ino.

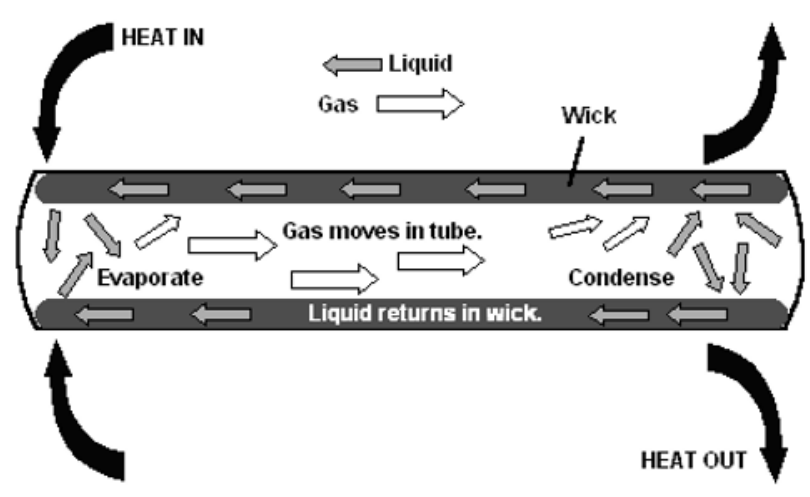

Fig. 3. Illustration of the principle of heat pipe.

\subsection{Specially modified heat pipe}

Functional element of the device is heat pipe. It consists of steel between the two circled the swirling sheets and flat bottoms along its sides. As material for the production of all metal parts were used austenitic chromium-nickel steel AISI 304 type designation. This is an anti-corrosion material with excellent corrosion resistance, formability and weld ability cold. Resistant to water, water vapor, humidity, edible acids, weak organic and inorganic acids.

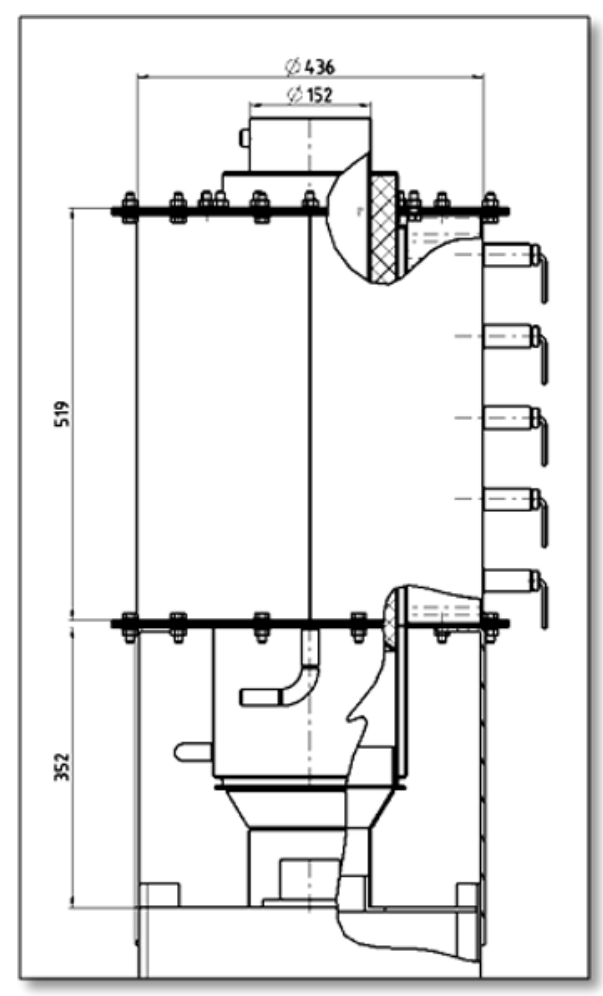

Fig. 4. Heat pipe with heat exchanger.

The resulting workspace is filled heat pipe working substance. As the working fluid was chosen water. The lower part of the heat pipe figure 4, ie evaporation part is exposed to the flue gases which extracts the necessary thermal energy. Evaporation and condensation of the heat pipe is separated by a metal ring.

Condensation of the heat pipe transfers its energy to the water heat exchanger. That consists of a cylindrical 
container with water for a total volume of 501 . Coat the container is fitted with temperature sensors that are placed in metal cases and firmly welded to the perimeter of the shell. In order to be prevented in the condensation heat transfer of heat from the flue pipe is insulated this section. Was used as insulation mat made of aluminosilicate fibers trade name SIBRAL with a classification temperature of $1260{ }^{\circ} \mathrm{C}$.

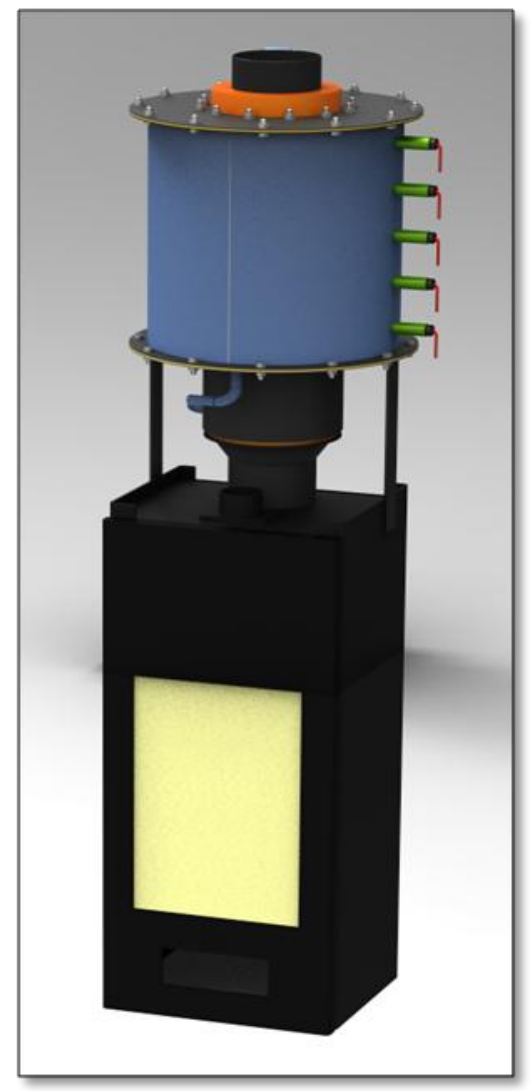

Fig. 5. 3D view of the experimental facility located at the heat.

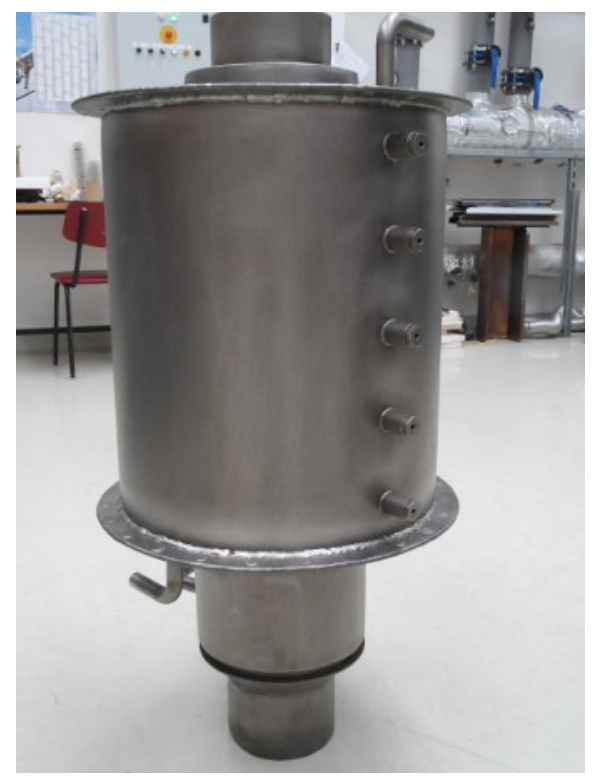

Fig. 6. Final version of real experimental device (side view).

This experimental device is needed now to do the measurement according to STN EN found his performance.

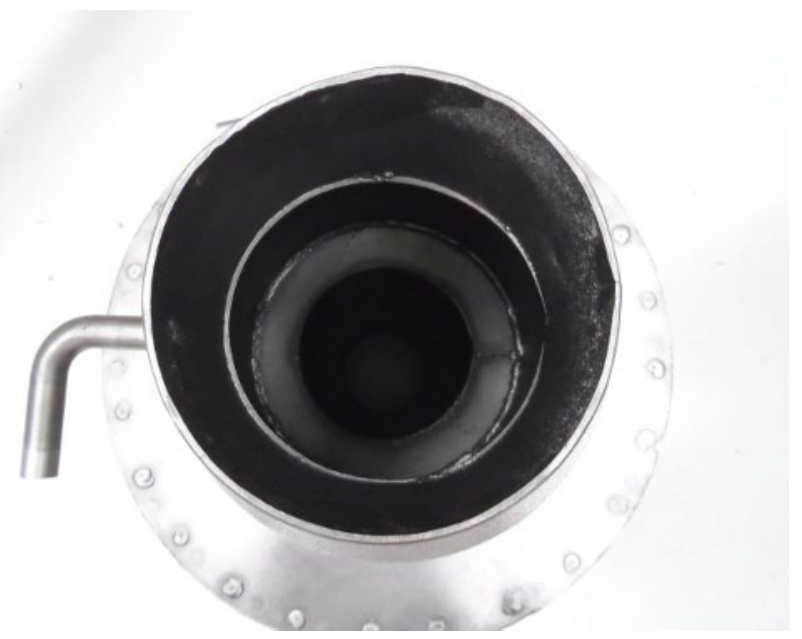

Fig. 7. Final version of real experimental device (bottom view).

\section{Measurement methodology of experimental device}

The experimental measurement was performed on the basis of European standards (EN 12897:2007), which lists the performance requirements and test methods for indirectly heated not ventilated - sealed storage water heaters with capacity up to $1000 \mathrm{l}$, which are suitable for connection to supply water pressure of $0.05 \mathrm{MPa}$ to 1.0 $\mathrm{MPa}$ and are equipped with controls and safety devices that prevent the operating temperature of drinking water in the tank exceeds $100^{\circ} \mathrm{C}$.

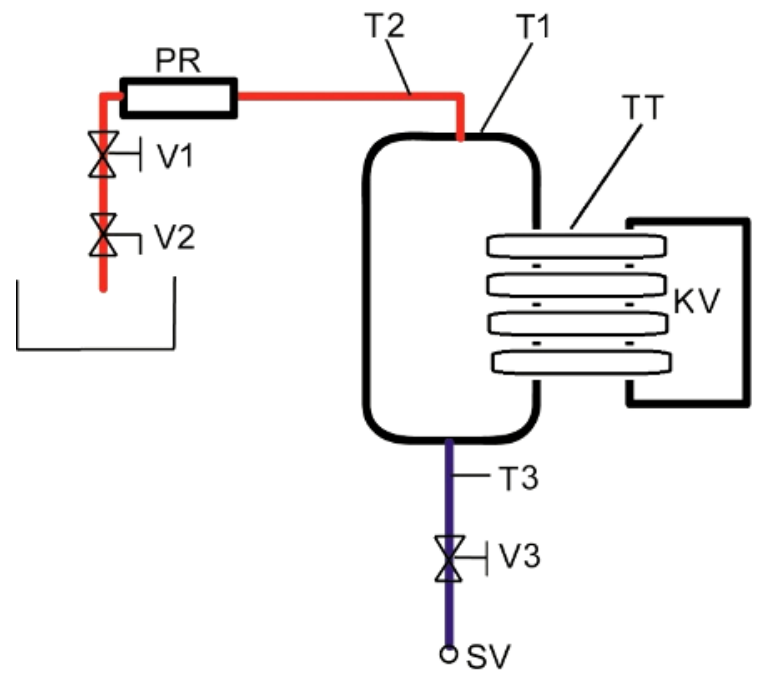

Fig. 8. Involvement of experimental device.

PR - flow meter; KV - fireplace insert; TT - heat pipes; V1, V3 - shut-off valves; V2 - control valves; T1, T2, T3 - PT100 temperature sensors; SV - cold water.

The experimental device is connected in figure 8. The water tank is filled, while print any entrapped air. Control valve V2 is closed. When the temperature T1 at the top of the tank water temperature reaches $15^{\circ} \mathrm{C}$, start the timer. When the temperature $\mathrm{T} 1$ reaches $60^{\circ} \mathrm{C}$, the heat source is disconnected. Measure the elapsed time and recorded as heating time. The system is then treated to stabilize about $1 \mathrm{~min}$. After about $1 \mathrm{~min}$. the valve V2 open the 
discharge begins, at the same time fully opened control valve V2 is set to flow downstream. In our case, it will flow $0.251 \mathrm{~s}^{-1}$, because it will be the maximum of 1001 water tank. While the flow rate is measured by the meter PR. Then starts the timer. When there is a drop in temperature T2 below $40{ }^{\circ} \mathrm{C}$, the valve $\mathrm{V} 2$ is closed, and measure the elapsed time and recorded, as the time of discharge. All readings are recorded in the measurement panel and the computer.

\section{Conclusion}

Based on theoretical and experimental research will be drawn theoretical consequences in the form of the output characteristics of a model that will serve to further use for the treatment of small heat sources for unconventional way of heating water. This possibility of heating the water in conjunction with small heat sources in the future seems like one of the options for reducing costs and energy for households.

\section{Acknowledgement}

This paper was prepared within the project VEGA no. $1 / 1290 / 12$.

\section{References}

1. K. Kaduchová, Diplomová práca (Žilina, 2010)

2. K. Kaduchová, M. Malcho, R. Lenhard, S. Gavlas, Transcom 9, 95-98 (2011)

3. STN EN 12897:2007, Vodárenstvo - Požiadavky na nepriamo vyhrievané neodvetrávané (uzatvorené) zásobnikové ohrievače vody

4. M. Malcho, S. Gavlas, Produktivita a inovácie 12, 25-28 (2011)

5. P. Nemec, A. Čaja, M. Malcho, Acta metallurgica slovaca conference 1, 159-162 (2011)

6. P. Nemec, A. Čaja, M. Malcho, Erin 5, 87-90 (2011)

7. M. Vantúch, M. Jakubský, M. Malcho, Transcom 9, 221-224 (2011)

8. J. Huzvar, R. Nosek, Power control and optimization 3, (2010) 